\title{
A Retrospective Study to Investigate Association among Age, BMI and BMD in the Postmenopausal Women
}

\author{
Jharna Shukla ${ }^{1}$, Purnima Dey Sarkar ${ }^{2}$, Angoorbala Bafna ${ }^{3}$, Nupur Shukla ${ }^{3}$ \\ ${ }^{1}$ Department of Biochemistry, College of Dental Science and Hospital, Rau \\ ${ }^{2}$ Department of Biochemistry, MGM College, Indore \\ ${ }^{3}$ Department of Biochemistry, Govt. Holkar Science College, Indore
}

\begin{abstract}
Bone strength (and, hence, fracture risk) is dependent on many qualities of bone, of which bone mineral density $(B M D)$ is the most commonly measured. Association between advancing age and lower body mass index (BMI) is an important risk factor in the occurrence of low BMD. This study was aimed at evaluation of the association among age, BMI and status of BMD among 159 age matched postmenopausal women who underwent Dual-Energy X-ray Absorptimetry (DEXA) scan. The study population was divided into three groups on the basis of body mass index (BMI) as normal weight, obese and severely obese. The mean bone mineral density (BMD) of obese and severely obese postmenopausal women was found to be significantly higher (P value $<0.001)$ as compared to the mean BMD of normal weight women. Significant negative correlation was found between the age and BMI except in severely obese group (P value <0.05). Age and BMD in all the three groups correlated negatively $(P$ value $<0.01)$ in all the three groups. BMD and BMI in the normal weight group significantly correlated negatively $(P$ value $<0.05)$ while a very weak positive but insignificant correlation existed between the same in the obese and severely obese postmenopausal women. The study revealed that with advancing age BMD is lowered and that higher BMI might have a positive influence (although not significant as observed in the present study) on the BMD. Other factors like exposure to sunlight, calcium intake, diet etc should also be investigated which could not be probed in the present study as it was a retrospective analysis.
\end{abstract}

Key words: BMD, BMI, Postmenopausal women, retrospective

\section{Introduction}

"Osteoporosis is characterized by low bone mass and an increased risk of fracture [1]. Osteoporosis is a progressive systemic skeletal disorder characterized by low bone mass and micro-architectural deterioration of bone tissue, with a consequent increase in bone fragility and susceptibility to fracture" [2]. India seems to have the highest prevalence of osteoporosis. With growing awareness of osteoporosis and its impact on life span especially in India, special attention is being paid to early detection, management and treatment of postmenopausal osteoporosis in women.

Osteoporosis is second only to cardiovascular disease as a leading health care problem, according to the World Health Organization. Worldwide, the lifetime risk for women to have an osteoporotic fracture is $30-40 \%$ [3]. Occurrence of osteoporosis is 10 years earlier in Indian people than in the West. It currently affects approximately one in three women and one in five men over age 50.

The disease is identified clinically by the occurrence of non traumatic fractures, especially in the lumbar spine (vertebral fractures) and forearm, and by the occurrence of femoral fractures after fall from height.

Fractures most commonly associated with osteoporosis are those of the hip, the vertebrae, and the wrist, and these are responsible for morbidity and excess mortality.

Early recognition and treatment of osteoporotic patients are crucial to the prevention of these fractures. In order for risk assessment to be effective and efficient, it must be practical and have high predictive value for the identification of fractures. Various tools have been developed for the prediction of fractures [4-8].

Bone densitometry using dual energy X-ray Absorptimetry (DEXA) is the "gold standard" for osteoporosis diagnosis and to assess fracture risk in clinical practice. Many clinical guidelines recommend risk factor assessment and measurement of bone mineral density (BMD) through dual energy X-ray Absorptimetry (DXA) to identify individuals at high risk of fracture [9-11]. Risk factors have been extensively characterized in women over the age of 65 years and are used in practice, often in combination, to predict fractures [12-15]. Prospective studies by Ravn et al. [16] and Bjarnason and Christiansen [17] indicates that early postmenopausal women who have low BMI lose more bone compared to those with higher BMI tertiles. Studies conducted by Van der Voort et al. $[18,19]$ illustrates that thinness is related to both osteoporosis and increased fracture risk; hence, low BMI is included in the risk assessment tools for evaluation of osteoporosis and osteoporotic fracture risk as suggested by Eddy et al. [20] and National Osteoporosis Foundation [21] and Black et al. [22]. 
The purpose of this study was to evaluate the relationship between bone mineral density and body mass index in the postmenopausal women.

\section{Materials And Methods}

A retrospective analysis of bone density data obtained from 159 postmenopausal women examined at Sampoorna Sodani diagnostics, Indore. Inclusion criteria were to be Indian, healthy 50 to 65 years old and within 1 to 10 years of menopause. They were divided into three groups on the basis of BMI as normal weight $(18 \leq \mathrm{BMI}<25)$, obese $(25 \leq \mathrm{BMI}<30)$ and severely obese $(\mathrm{BMI}>30)$. The exclusion criteria were $\mathrm{BMI}>40$, history of chronic diseases, use of corticosteroids and antireabsorptive drugs and hormone replacement therapy. All these statements were obtained by a questionnaire applied before the exam was done and answered by the patient themselves.

Anthropometric measures included weight $(\mathrm{W})$, height $(\mathrm{H})$ and body mass index $(\mathrm{BMI})$ calculated as $\mathrm{W} / \mathrm{H}^{2}(23,24)$. Patients were divided in normal weighted $\left(18.5 \leq \mathrm{BMI}<24.9 \mathrm{Kg} / \mathrm{m}^{2}\right)$ and overweight or obese women $\left(25 \leq \mathrm{BMI}<40 \mathrm{Kg} / \mathrm{m}^{2}\right)$. We hypothesized that any grade of excessive weight could be a protective factor for bone density.

Bone mineral density (BMD) was measured at left femur by Dual X-ray Absorptimetry (DXA) using the lunar DPX DXA system (analysis version: 10.51) manufactured by GE health care.

\section{Statistics}

Statistical analysis was performed with SPSS software (version 20.0). Data were expressed as mean \pm SD.

Groups were compared by Student's $t$ test. Pearson simple correlation analysis was used to evaluate the interrelationship between parameters.

\section{Results}

TABLE1. Comparison of Anthropometric data of study groups

\begin{tabular}{lcccc}
\hline & Normal Weight & Obese & Severely Obese & P value \\
\hline Age & $60.46 \pm 9.50$ & $57.98 \pm 8.91$ & $58.56 \pm 9.01$ & NS \\
BMI & $22.32 \pm 2.12$ & $27.01 \pm 1.42$ & $33.83 \pm 3.33$ & $<0.001$ \\
BMD g/cm ${ }^{2}$ & $0.773 \pm 0.12$ & $0.858 \pm 0.15^{*}$ & $0.835 \pm 0.14^{*}$ & $<0.001$ \\
\hline
\end{tabular}

* Mean difference of BMD of obese and severely obese not significant.

Table 1 depicts the statistical significance of mean differences amongst the different groups. There was no significant difference in the mean ages of the study group individuals. A significant difference in the mean BMI values ( $\mathrm{P}$ value $<0.001)$ among the groups was observed. Mean BMD of the normal weight when compared with mean BMD of obese and severely obese respectively was significantly different ( $\mathrm{P}$ value $<0.001)$. The BMD was found to be significantly higher in obese and severely obese postmenopausal women as compared to the BMD of normal weight postmenopausal women. But the mean BMD values of obese and severely obese groups did not differ significantly.

TABLE 2 Correlation amongst the variables of various groups

\begin{tabular}{lcccc}
\hline & Normal Weight & Obese & Severely Obese & P value \\
\hline & & & & \\
Age vs. BMI & -0.261 & -0.139 & $0.101^{*}$ & 0.05 \\
Age vs. BMD & -0.448 & -0.657 & -0.516 & 0.01 \\
BMI vs. BMD & -0.284 & $0.01 *$ & $0.013^{*}$ & 0.05 \\
\hline
\end{tabular}

* Not significant

Table 2 depicts the correlation coefficients between the variables in the study groups. A significant negative correlation between age and BMI in the normal weight and obese postmenopausal women was observed while in the severely obese group age did not correlate with the BMI significantly.

Age and BMD correlated negatively with each other in all the groups and the correlation was significant at the 0.01 level of significance which suggests that advancing age is associated with low BMD. 
BMI and BMD correlated negatively at 0.05 significance level in the normal weight group but no significant correlation was found between both variables in the obese and the severely obese group, although the correlation was positive.

\section{Discussion}

Menopause is associated with an imbalance in bone metabolism, and the first five to ten years after menopause is the period of higher bone turnover and bone loss (25, 26). Approximately $35 \%$ of postmenopausal women lose significant amounts of bone mineral during this period ("fast losers") and are at a higher risk for osteoporosis and fragility fractures later in life (27). The decline in ovarian estrogen production is the main determinants of this imbalance, but estradiol serum levels explain only a small proportion of inter individual variance of BMD and bone loss. Therefore, many other factors seem to be involved, such as age, lean and fat mass, exercise, race, smoke, and genetic factors. Ribot and Albala $(28,29)$ previously described that obese women have higher bone mass after menopause than normal weighted age-matched women, especially at lumbar spine and femoral neck. The present study also showed significantly higher mean BMD in the obese and severely obese postmenopausal women as compared to the mean BMD of normal weight postmenopausal women.

The correlation between BMD at the femoral neck and BMI observed was highly positive in a crosssectional study conducted among postmenopausal women by Steinschneider et al. [30]. The findings suggest that the increased BMD commonly reported in overweight women may result from soft tissue interference with BMD determination by DEXA. Studies by Felson et al. [31], Nguyen et al. [32] and Baheiraei et al. [33] reported the consistent finding that lower BMI was associated with lower BMD. Findings of the present study however vary in that a significant negative correlation between the BMI and BMD was observed in the normal weight group while an insignificant positive correlation was observed between the BMI and BMD in the obese and severely obese postmenopausal women.

The previous literature of Jones et al. [34], and Nguyen et al. [35] indicated that advancing age was associated with low BMD. In this study also a negative correlation between age and bone mineral density was observed in postmenopausal women of all the groups.

\section{Conclusion}

This study is an attempt to address one of the important public health problems which can be controlled if preventive measures are taken at an early stage. More about the risk factors could not be investigated as this is a retrospective case record analysis. The results of this study suggest that advancing age and lower BMI are important risk factors for the occurrence of low BMD and that any grade of obesity might have a positive influence on the BMD. Further studies are required to investigate the effect of other factors like exposure to sunlight, calcium intake, and other habits like smoking, diet, and so forth.

\section{References}

[1]. Sambrook P, Cooper C, Osteoporosis. Lancet, 2006, 367:2010-2018

[2]. Axelrod DW, Teitelbaum SL. Results of long-term cyclical etidronate therapy: bone histomorphometry and clinical correlates, $J$ Bone Miner Res. 1994, 9S1:136.

[3]. Moyad MA. Preventing male osteoporosis: prevalence, risks, diagnosis and imaging tests, Urol Clin N Am., 2004, 31:321-30.

[4]. Black DM, Steinbuch M, Palermo L, Dargent-Molina P, Lindsay R, Hoseyni MS, et al. An Assessment Tool for Predicting Fracture Risk in Postmenopausal Women, Osteoporos Int. 2001, 12:519-28.

[5]. Cadarette SM, Jaglal SB, Kreiger N, McIsaac WJ, Darlington GA, Tu JV. Development and validation of the Osteoporosis Risk Assessment Instrument to facilitate selection of women for bone densitometry, CMAJ. 2000; 162:1289-94.

[6]. Lydick E, Cook K, Turpin J, Melton M, Stine R, Byrnes C. Development and validation of a simple questionnaire to facilitate identification of women likely to have low bone density. Am J Managed Care, 1998, 4:37-48.

[7]. Robbins J, Aragaki AK, Kooperberg C, Watts N, Wactawski Wende J, Jackson RD, et al. Factors associated with 5 - Year risk of hip fracture in postmenopausal women, JAMA. 2007, 298:2389-98.

[8]. Kanis JA, Johnell O, Oden A, Johansson H, McCloskey E. FRAX and the assessment of fracture probability in men and women from the UK, Osteoporosis Int., 2008,19:385-97

[9]. Brown JP, Josse RG , Clinical practice guidelines for the diagnosis and management of osteoporosis in Canada, CMAJ, 2002,167:S1-S34

[10]. National Osteoporosis Foundation, Physician's guide to the prevention and treatment of osteoporosis, National Osteoporosis Foundation, Washington, DC, 2003

[11]. Kanis JA, Diagnosis of osteoporosis and assessment of fracture risk, Lancet, 2002, 359:1929 1936

[12]. Cummings SR, Nevitt MC, Browner WS, Stone K, Fox KM, Ensrud KE et al, Risk factors for hip fracture in white women. Study of Osteoporotic Fractures Research Group. N Engl J Med, 1995, 332:767-73

[13]. Van Staa TP, Leufkens HG, Abenhaim L, Zhang B, Cooper C, Use of oral corticosteroids and risk of fractures, J Bone Miner Res 2000, 15:993-1000

[14]. Kanis JA, Borgstrom F, De Laet C, Johansson H, Johnell O, Jonsson B et al, Assessment of fracture risk, Osteoporos Int, 2005, 16:581-89

[15]. Kanis JA, Oden A, Johnell O, Johansson H, De Laet C, Brown J et al, The use of clinical risk factors enhances the performance of BMD in the prediction of hip and osteoporotic fractures in men and women., Osteoporos Int, 2007, 18:1033-1046 
[16]. Ravn P., Cizza G., Bjarnason N. H. "Low body mass index in early postmenopausal women. Early Postmenopausal Intervention Cohort (EPIC) study group," Journal of Bone and Mineral Research, vol. 14, pp. 1622-1627, 1999.

[17]. Bjarnason N. H. and Christiansen C., "The influence of thinness and smoking on bone loss and response to hormone replacement therapy in early postmenopausal women," Journal of Clinical Endocrinology and Metabolism, vol. 85, no. 2, pp. 590-596, 2000.

[18]. Van Der Voort D. J. M., Brandon S., Dinant G. J., and Van Wersch J. W. J., "Screening for osteoporosis using easily obtainable biometrical data: diagnostic accuracy of measured, self-reported and recalled BMI, and related costs of bone mineral density measurements," Osteoporosis International, vol. 11, no. 3, pp. 233-239, 2000.

[19]. Van der Voort D. J. M., Geusens P. P., and Dinant G. J., "Risk factors for osteoporosis related to their outcome: fractures," Osteoporosis International, vol. 12, no. 8, pp. 630-638, 2001.

[20]. Eddy D. M., Johnston C. C., Cummings S. R. et al., "Osteoporosis: review of the evidence for prevention, diagnosis, and treatment and cost-effectiveness analysis. Status report," Osteoporosis International, vol. 8, no. 4, pp. 1-88, 1998.

[21]. National Osteoporosis Foundation, Osteoporosis. Physician's Guide to Prevention and Treatment of Osteoporosis, National Osteoporosis Foundation, Washington, DC, USA, 1998.

[22]. Black D. M., Steinbuch M., Palermo L. et al., "An assessment tool for predicting fracture risk in postmenopausal women," Osteoporosis International, vol. 12, no. 7, pp. 519-528, 2001.

[23]. World Health Organization. Physical status: the use and interpretation of anthropometry. Report of a WHO expert committee. Technical report series no. 854. Geneva: WHO, 1995.

[24]. Garrow JS, Webster J. Quetlet's index (W/H2) as a measure of fatness. Int J Obesity 1985, 9:147-53.

[25]. Hla MM, Davis HM, Ross PD, Yates AJ, Wasnich RD, Ravn P, et al. Relation between body composition and biochemical markers of bone turnover among early postmenopausal women, J Clin Densitom 2000, 3(4):365-71.

[26]. Delmas PD. Biochemical markers for the assessment of bone turnover. In: Osteoporosis: etiology, diagnosis and management. 2nd edition. Philadelphia: Lippincott-Raven, 1995. pp. 319-33.

[27]. Riis BJ. The role of bone turnover in the pathophysiology of osteoporosis, Br J Obstet Gynaecol 1996, 103:9-15.

[28]. Ribot C, Tremollieres F, Pouilles JM. The effect of obesity on postmenopausal bone loss and the risk of osteoporosis, Adv Nutr Res 1994, 9:257-71.

[29]. Albala C, Yanez M, Devoto E, Sostin C, Zeballos L, Santos JL. Obesity as a protective factor for postmenopausal osteoporosis, Int J Obes Relat Metab Disord 1996, 20(11):1027-32

[30]. Steinschneider M., Hagag P., Rapoport M. J. , and Weiss M., Discordant effect of body mass index on bone mineral density and speed of sound, BMC Musculoskeletal Disorders, vol. 4, article 1, pp. 1-6, 2003.

[31]. Felson D. T., Zhang Y, Hannan M. T., and Anderson J. J., Effects of weight and body mass index on bone mineral density in men and women: the Framingham study, Journal of Bone and Mineral Research, vol. 8, no. 5, pp. 567-573, 1993.

[32]. Nguyen T. V., Center J. R., and Eisman J. A., Osteoporosis in elderly men and women: effects of dietary calcium, physical activity, and body mass index, Journal of Bone and Mineral Research, vol. 15, no. 2, pp. 322-331, 2000.

[33]. Baheiraei A., Pocock N. A., Eisman J. A., Nguyen N. D., and Nguyen T. V., Bone mineral density, body mass index and cigarette smoking among Iranian women: implications for prevention, BMC Musculoskeletal Disorders, vol. 6, article 34, 2005.

[34]. Jones G., Nguyen T., Sambrook P., Kelly P. J., and Eisman J.A., Progressive loss of bone in the femoral neck in elderly people: longitudinal findings from the Dubbo osteoporosis epidemiology study, British Medical Journal, vol. 309, no. 6956, pp. 691-695, 1994.

[35]. Nguyen T. V., Sambrook P. N., and Eisman J. A., Bone loss, physical activity, and weight change in elderly women: the dubbo osteoporosis epidemiology study, Journal of Bone and Mineral Research, vol. 13, no. 9, pp. 1458-1467, 1998. 